[논문] 열처리공학회지, 제 26 권 제 5 호(2013)

J. of the Korean Society for Heat Treatment.

http://dx.doi.org/10.12656/jksht.2013.26.5.219

\title{
$\mathrm{Cu}$ 가 함유된 구상흑연주철의 $380^{\circ} \mathrm{C}$ 에서 오스템퍼링 시 $\mathrm{Mo}$ 이 기계적 특성에 미치는 영향
}

\author{
김 기 엽 \\ 한국폴리텍대학 대구캠퍼스 신소재응용과
Effects of Mo on the Mechanical Properties of Ductile Cast Iron with Cu Austempered at $380^{\circ} \mathrm{C}$

\section{G.Y. Kim} \\ *Dept. of Advanced Material Application, Daegu Campus of Korea Polytechnic, Daegu 703-721, Korea
}

\begin{abstract}
In this study, we investigated effect of Mo addition on mechanical properties of Cu added ADI. Ductile cast iron specimens were austenitized at $900^{\circ} \mathrm{C}$ for $150 \mathrm{~min}$ and then austempered at $380^{\circ} \mathrm{C}$ for the various time periods from $15 \mathrm{~min}$ to $480 \mathrm{~min}$. Mo added ADI had a higher volume fraction of retained austenite, and the volume fraction of retained austenite was determined by XRD analysis. As decreasing volume fraction of retained austenite, the elongation was also decreased as expected. But the UTS and yield strength were not decreased.
\end{abstract}

(Received July 4, 2012; Revised July 15, 2013; Accepted July 19, 2013)

Key words : Effects of Mo, Austempering, Austempered Ductile Cast Iron, Heat Treatment

\section{1. 서 론}

최근 자동차 산업의 핵심 과제 중 하나는 가볍고 기계적 특성이 우수하며 가격이 저렴한 소재의 개 발이다. 이에 부합하는 재료의 하나로서 ADI (austempered ductile cast iron)를 들 수 있다. 여 기서 ADI란 오스템퍼링이라는 항온 열처리를 하여 구상흑연주철이 갖는 기지조직인 펄라이트와 페라이 트를 우수한 특성을 갖는 오스페라이트라는 조직으로 변태 시킨 것을 말한다. 이러한 $\mathrm{ADI}$ 는 지금까지 기 계나 차량 등의 각종 부품제조에 주로 사용하고 있 는 주강(cast steel)이나 단조강(forged steel)에 필 적하거나 그 이상의 기계적 성질을 나타내고 있다.

일본 등의 선진 각 국에서는 1980년 초부터 주철 의 오스템퍼링에 관한 연구를 시작하여 자동차 및 부 품 등에 부분적으로 실용화를 이루고 있는 반면에 국 내의 경우는 80 년대 중반에 와서 $\mathrm{ADI}$ 에 대한 소개 가 시작되어 지금까지 연구가 진행되고 있지만 아직 실용화가 널리 이루어지지 않고 있는 실정이다[1-2].

Corresponding author. E-mail : gykim1021@nate.com Copyright (c) The Korean Society for Heat Treatment
$\mathrm{ADI}$ 는 비교적 많은 양의 잔류 오스테나이트를 함 유하고 있어 인성이 크므로 열처리 시 균열 발생이 거의 없고 내마모성이 우수하며, 흑연의 존재로 인해 강에 비하여 비중이 $10 \%$ 정도 낮아 그만큼의 경량 화 효과를 가져 올 수 있는 장점이 있다. 또 구상 흑연주철에 비해 두 배 이상의 인장강도 $(850 \mathrm{MPa}$ $1600 \mathrm{MPa}$ )를 갖고, 주철에서 얻을 수 없는 높은 연 신율( $10 \%)$ 을 가지며 제조 시 원가절감 효과가 크 므로 이에 대한 관심이 점차 고조되고 있다[3-5].

하지만 $\mathrm{ADI}$ 의 단점으로는 열처리 가능한 두께에 제한이 있다는 것이다. 두꺼운 부분의 열처리를 위해 서는 합금 원소의 첨가는 불가피 하다. 경화능의 향 상을 위해 주로 첨가되는 합금 원소로는 $\mathrm{Ni}, \mathrm{Mn}$, $\mathrm{Mo}, \mathrm{Cu}$ 등이 잘 알려져 있으며, 단독으로 첨가 되 었을 때는 $\mathrm{Mo}>\mathrm{Mn}>\mathrm{Ni}>\mathrm{Cu}$ 순으로 경화능 정 도가 나타나는 것이 알려져 있다[6].

그러나 이들 합금원소가 첨가된 소재를 이용하기 위해서는 열처리 조건에 따른 기계적 특성에 대한 연구가 필요하게 된다. 경화능 향상을 위해 첨가된 
Table 1. Chemical composition of material used

\begin{tabular}{c|c|c|c|c|c|c|c|c|c}
\hline \multicolumn{1}{c|}{ Alloys } & $\mathrm{C}$ & $\mathrm{Si}$ & $\mathrm{Mn}$ & $\mathrm{Mg}$ & $\mathrm{P}$ & $\mathrm{S}$ & $\mathrm{Cu}$ & $\mathrm{Mo}$ & $\mathrm{Fe}$ \\
\hline GCD 450 & $3.6 \sim 3.8$ & $2.2 \sim 2.8$ & $0.15 \sim 1$ & $0.03 \sim 0.06$ & $0.03 \downarrow$ & $0.002 \downarrow$ & - & - & bal. \\
\hline Mo- Free & $3.6 \sim 3.8$ & $2.2 \sim 2.8$ & $0.15 \sim 1$ & $0.03 \sim 0.06$ & $0.03 \downarrow$ & $0.002 \downarrow$ & 0.6 & - & bal. \\
\hline Mo 0.4 wt\% & $3.6 \sim 3.8$ & $2.2 \sim 2.8$ & $0.15 \sim 1$ & $0.03 \sim 0.06$ & $0.03 \downarrow$ & $0.002 \downarrow$ & 0.6 & 0.4 & bal. \\
\hline
\end{tabular}

원소들은 보통 CCT 곡선에서의 펄라이트 nose와 베이나이트 nose 의 시간이 길어짐을 알 수 있다 [7]. 즉, 열처리 시간이 많이 걸린다는 것을 의미하 고, 제품의 열처리 시 제조단가의 상승을 야기하게 된다.

$\mathrm{Cu}$ 는 비교적 저렴한 가격에 경화능을 향상시킬 수 있는 소재로서 널리 사용되고 있다. 하지만 $\mathrm{Cu}$ 만 첨가 하여서는 원하는 경화능을 얻을 수 없는 경우 가 있기 때문에 이에 본 연구에서는 합금원소인 $\mathrm{Mo}$ 을 첨가 하였을 때의 열처리 조건에 따른 기계적 물성을 평가하고자 한다.

\section{2. 실험방법}

\section{1 용해 및 주조}

본 실험에 사용한 구상흑연주철은 Table 1 과 같이 상용으로 사용되는 $\mathrm{GCD} 450$ 의 조성에 $0.6 \% \mathrm{Cu}$ 만 첨가한 것과 $0.6 \% \mathrm{Cu}$ 와 $0.4 \% \mathrm{Mo}$ 가 첨가된 2 가지를 사용하였다. 시료의 제조는 $400 \mathrm{Kg}$ 고주파 유도로를 사용하여 대기중에서 선철, 고철 및 가탄제 및 합금 원소인 $\mathrm{Cu}$ 와 $\mathrm{Mo}$ 를 첨가하여 용해한 후 슬래그를 제거하고, $\mathrm{Fe}-50 \% \mathrm{Si}$ 합금으로 $\mathrm{Si}$ 양을 조절하였다. 용탕의 온도를 $1500^{\circ} \mathrm{C}$ 로 상승시켜 미리 예열한 레 이들(ladle)의 바닥에 $\mathrm{Fe}-45 \% \mathrm{Si} \sim 4.5 \% \mathrm{Mg}$ 합금의 구상화처리제를 넣고 $1470^{\circ} \mathrm{C}$ 에서 구상화 처리를 실 시 한 후 즉시 $\mathrm{Fe}-75 \% \mathrm{Si}$ 합금으로 후접종 하여 $1390^{\circ} \mathrm{C}$ 정도에서 사형 Y-block에 주입하여 제조하였 다. 제작된 Y-block은 KS D 4302에 명시된 A호를 이용하였다.

\section{2 시편 제작}

주조된 Y-block을 압탕부분을 절단한 하고 남은 부분을 Fig. 1과 같은 형상으로 ASTM E8M에 나 타난 규격에 맞게 선반 공정을 통해 인장시편을 제 작하였다.

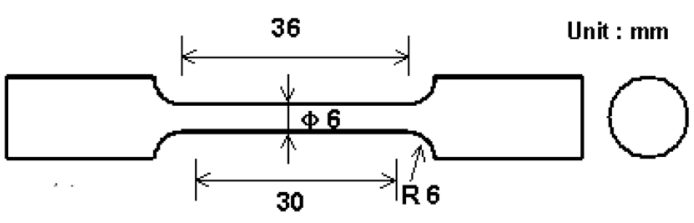

Fig. 1. The dimension of tensile strength test specimen.

Table 2. Conditions of heat treatment

\begin{tabular}{c|c|c|c}
\hline \multicolumn{2}{c|}{ Austenitizing } & \multicolumn{2}{c}{ Austempering } \\
\hline Temp. $\left[{ }^{\circ} \mathrm{C}\right]$ & Time [min] & Temp. $\left[{ }^{\circ} \mathrm{C}\right]$ & Time $[\mathrm{min}]$ \\
\hline & & & 15 \\
& & & 30 \\
900 & \multirow{3}{*}{150} & 380 & 60 \\
& & & 120 \\
& & & 240 \\
& & & 480 \\
\hline
\end{tabular}

\section{3 열처리}

열처리로의 온도를 $900^{\circ} \mathrm{C}$ 로 조절하여 오스테나이 타이징 실시한 후, $380^{\circ} \mathrm{C}$ 의 염욕에서 오스템퍼링을 실시하였으며, 그에 대한 세부열처리 내용은 Table 2에 나타내었다.

\section{4 물성 평가}

미세조직 분석을 위해 시편을 폴리싱 한 후, $3 \%$ $\mathrm{Nital}$ 로 에칭 하여 광학현미경으로 관찰하였다.

인장 시험은 Universal Test Machine(Instron 8501)을 사용하여, 크로스헤드의 이동속도를 1.5 $\mathrm{mm} / \mathrm{min}$ 으로 고정하여 상온에서 실시하였다.

경도 시험은 로크웰 경도기(Daekyung DTR $200)$ 를 사용하여, C-scale $(150 \mathrm{~kg})$ 로 측정하였으며, 각 열처리 조건당 5 회씩 실시하였다.

마지막으로 상(phase) 분석은 $\mathrm{XRD}$ (Philips Analytical X- Ray) 장비를 사용하여 잔류 오스테나 이트(retained austenite)량을 측정하였다. 


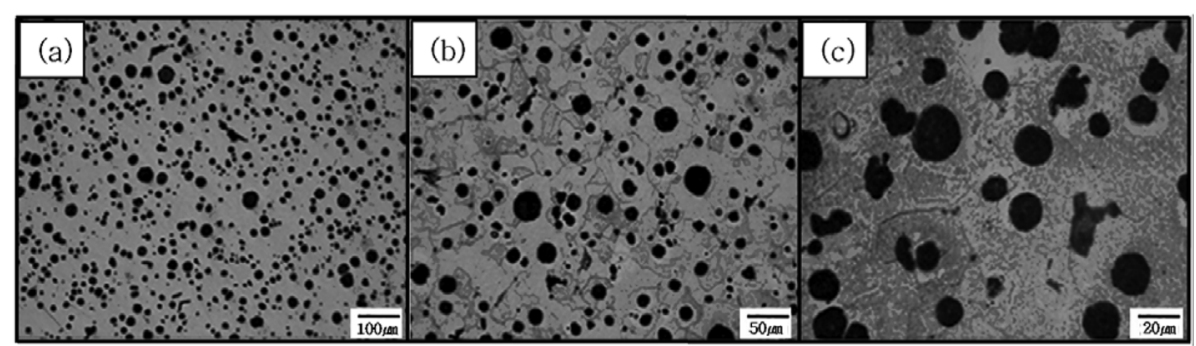

Fig. 2. Microstructures of as-cast ductile cast iron (GCD450 alloy) specimens (a) before etching, (b) after etching, (c) after etching.

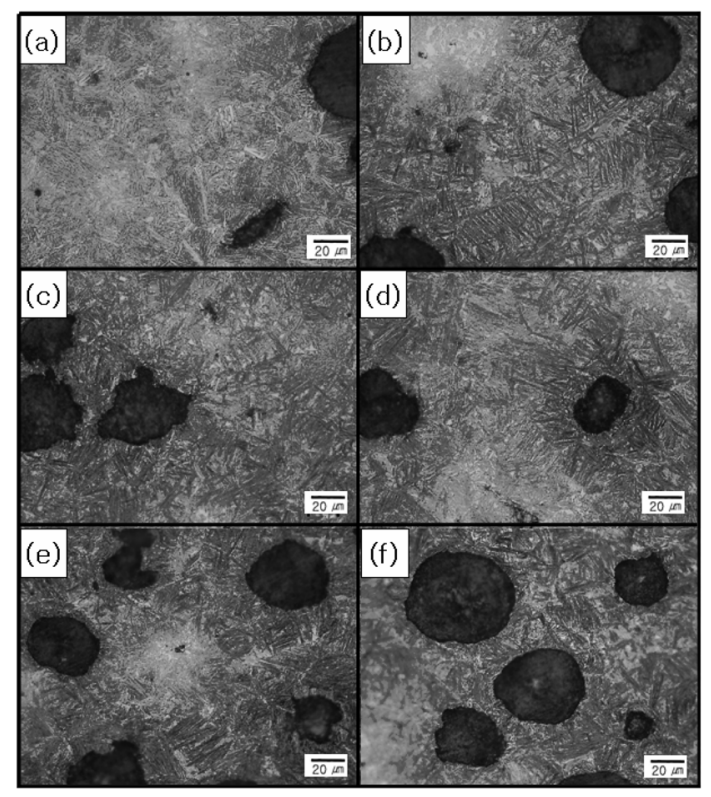

Fig. 3. Microstructures of Mo-free specimens austempered at $380^{\circ} \mathrm{C}$ for (a) $15 \mathrm{~min}$, (b) $30 \mathrm{~min}$, (c) $60 \mathrm{~min}$, (d) $120 \mathrm{~min}$, (e) $240 \mathrm{~min}$, (f) $480 \mathrm{~min}$.

\section{3. 결과 및 고찰}

\section{1 미세조직}

$\mathrm{GCD} 450$ 의 주방상태 미세조직 사진을 Fig. 2에 나타내었다. 열처리 전 미세조직의 주 기지조직은 페 라이트이며, 흑연의 구상화와 주조 결함에 대하여 큰 문제점이 없다는 것을 확인 할 수 있다.

일반적으로 오스템퍼링 열처리를 실시하면 오스테 나이트 내부에 페라이트가 성장하여 두 상이 공존하 는 오스페라이트라는 조직이 나타난다. 특히 $380^{\circ} \mathrm{C}$ 의 오스템퍼링 온도는 상부 오스페라이트 영역으로서 오스페라이트 상이 깃털의 형상으로 나타난다. 이와 같은 상부 오스페라이트는 오스테나이타이징 후

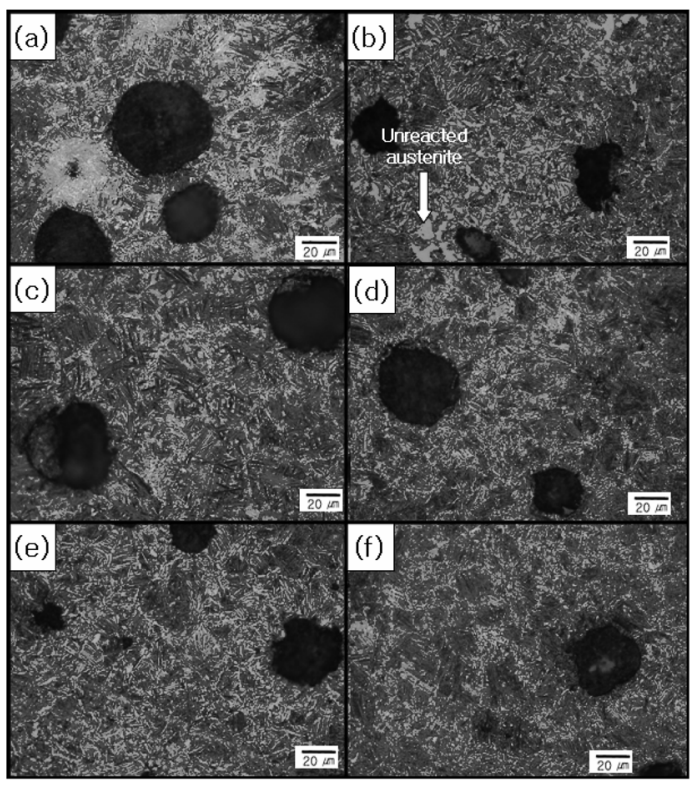

Fig. 4. Microstructures of $0.4 \%$ Mo specimens austempered at $380^{\circ} \mathrm{C}$ for (a) $15 \mathrm{~min}$, (b) $30 \mathrm{~min}$, (c) $60 \mathrm{~min}$, (d) $120 \mathrm{~min}$, (e) $240 \mathrm{~min}$, (f) $480 \mathrm{~min}$.

퀜칭 시 온도의 차이가 적어서 핵생성 사이트가 적 어지므로 페라이트는 조대하게 성장하고, 오스템퍼링 온도가 높기 때문에 페라이트로부터 미변테 오스테나 이트로의 탄소 확산이 활발하여 잔류 오스테나이트 영역이 넓어짐으로 조대한 오스페라이트 조직이 생성 된다.

Fig. 3, Fig. 4는 인장시편에서 채취한 시편의 $900^{\circ} \mathrm{C}$ 에서 오스테나이타이징 후, $380^{\circ} \mathrm{C}$ 에서 15,30 , $60,120,480 \mathrm{~min}$ 동안 오스템퍼링한 시편의 500 배 확대한 광학 현미경 관찰 조직이다. 시간이 경과함에 따라 두 시편 모두 기지조직이 오스페라이트로 변화 되어 가는 것을 확인 할 수 있다. 그러나 $\mathrm{Mo}$ 이 첨 가된 시편의 조직사진인 Fig. 4에서의 화살표 부분 


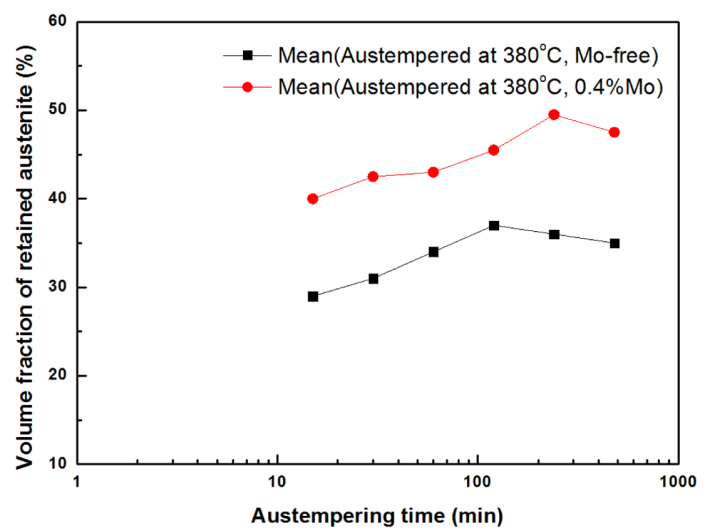

Fig. 5. Variation of volume fraction of retained austenite with austempering time.

은 벌크형상의 미변태 오스테나이트가 관측된다[8]. 또한 $\mathrm{Mo}$ 이 함유된 시편의 오스페라이트 조직이 더 미세화 되어있음을 알 수 있다.

\section{2 잔류 오스테나이트 분율의 변화}

Fig. 5 에서 볼 수 있듯이 $\mathrm{Mo}^{\circ}$ 이 함유된 시편의 잔 류 오스테나이트의 양이 $\mathrm{Mo}$ 가 함유되지 않은 것보 다 높게 나오고 있다. 오스템퍼링 중에 발생하는 1 단계 반응은 페라이트의 생성으로 인해 탄소가 오스 테나이트로 이동하여 고탄소의 오스테나이트가 생성, 잔류시키는 것이다. 이런 1 단계반응이 기지에 분포되 어있는 $\mathrm{M}$ o에 의해 $\mathrm{C}$ 의 이동을 방해하여 페라이트 의 성장이 늦었으며, 그에 따라 잔류오스테나이트 양 이 더 증가한 것으로 판단된다.

그리고 오스템퍼링의 시간이 길어질 경우, 계속되 는 페라이트의 증가로 오스테나이트의 탄소함량이 일 정 이상 증가하여 카바이드가 생성되는 제 2단계 반 응이 일어난다. 이와 같은 2 단계 반응에 의하여 $\mathrm{Mo}$ 이 함유되지 않은 시편에서는 $120 \mathrm{~min}$ 을 기점으로 잔류오스테나이트 분율이 감소함을 볼 수 있다. 그러 나 $\mathrm{Mo}$ 의 첨가로 인해서 $240 \mathrm{~min}$ 으로 지연되었다. 이는 $\mathrm{Mo}$ 가 페라이트 안정화 원소로서 카바이드의 생성을 억제하였기 때문이다.

즉, $\mathrm{Mo}$ 의 첨가는 탄소의 이동을 억제함으로서 전 체적인 반응에 걸리는 시간을 뒤로 지연시킴과 동 시에 잔류오스테나이트의 량을 증가시킨다고 할 수 있다.

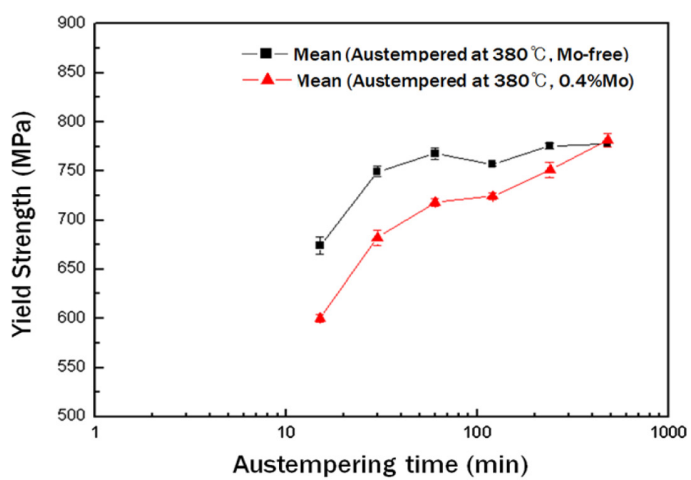

(a)

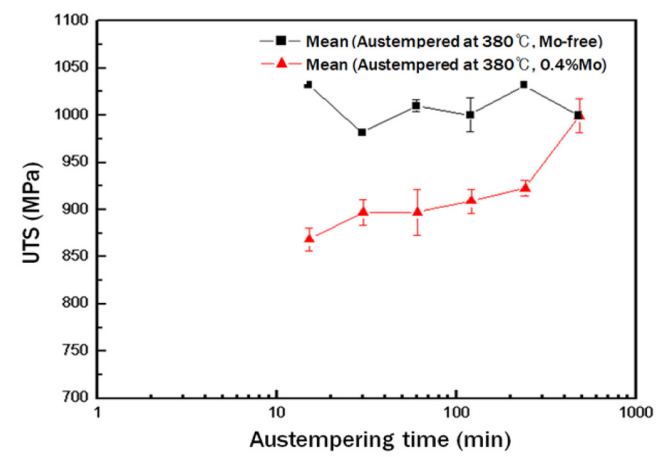

(b)

Fig. 6. Variation of strength with austempering time. (a) Yield Strength, (b) Ultimate tensile strength.

\section{3 인장 및 항복 특성의 변화}

Fig. 6 은 인장 테스트 결과를 나타낸 그래프이다. 인장강도의 변화를 살펴보면 합금원소인 $\mathrm{Mo}$ 의 첨가 에 의해서 인장강도가 $\mathrm{Mo}$ 이 첨가되지 않은 시편과 비교해 보면 전체적으로 같은 시간에 비해 떨어짐을 알 수 있다. 하지만 이것은 $\mathrm{Mo}$ 이 첨가됨으로 인해 프로세싱 윈도우가 뒤로 밀리게 되어 아직 1 단계 변 태가 끝나지 않았기 때문이다. $\mathrm{Mo}$ 이 함유되지 않은 시편에서의 고탄소 오스테나이트의 양만큼을 형성하 기 위해 $\mathrm{Mo}$ 이 첨가된 시편에서는 더 많은 시간을 요구한다는 것이다. 이는 $480 \mathrm{~min}$ 이 지나서도 아직 인장강도는 계속 상승하고 있다는 점으로도 확인할 수 있다. 그러나 $\mathrm{Mo}$ 이 첨가되지 않은 시편에서는 $30 \mathrm{~min}$ 이상에서 크게 상승하거나 내려가는 경향은 보이지 않았다.

항복강도 역시 인장강도와 비슷한 경향을 보여주고 있다 $\mathrm{Mo}$ 이 첨가된 시편은 항복강도가 계속 증가하 고 있지만 $\mathrm{Mo}$ 이 첨가되지 않은 시편에서는 30 


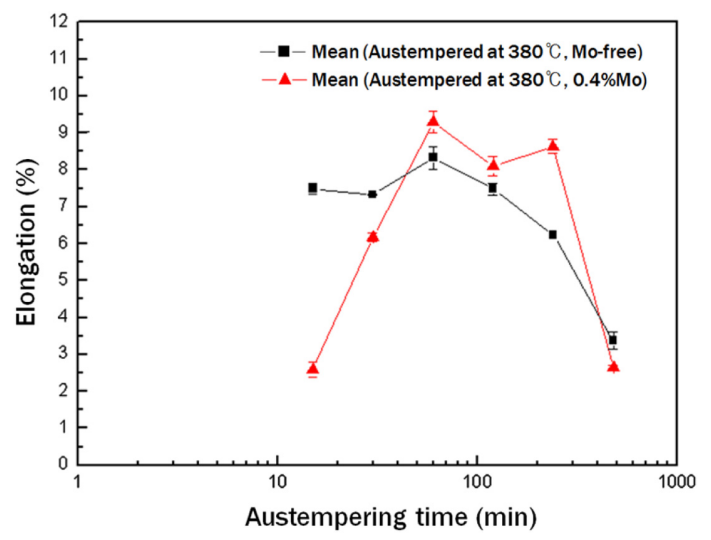

Fig. 7. Variation of elongation with austempering time.

$\min$ 이후로는 크게 증가하거나 감소하지 않는 정적 인 상태가 유지되고 있다. 하지만 XRD 분석을 통 한 잔류오스테나이트 분율은 $\mathrm{Mo}$ 이 함유된 시편에서 는 $240 \mathrm{~min}, \mathrm{Mo}$ 이 없는 시편에서는 $120 \mathrm{~min}$ 을 기 점으로 감소하는 것이 관찰 되었다. 이는 2 단계 반 응이 시작되었음을 의미한다.

하지만 잔류 오스테나이트 분율의 측정에서 분율이 감소하기 시작하는 시간에서의 인장, 항복강도는 떨 어지지 않았다. 이는 2 단계 반응 초기에 생성되는 탄화물의 양이 인장, 항복특성에 미치는 영향은 미비 하다는 것을 생각할 수 있다. 그러나 내충격치에는 심각한 악영향을 미친다고 보고되어 있다[9].

\section{4 연신율의 변화}

Fig. 7은 시간에 따른 연신율 변화를 나타낸 그래 프이다. Mo이 함유된 시편에서의 연신율 특성은 초 기에 급격하게 증가하다가 $240 \mathrm{~min}$ 이 지난 후에 급 격히 감소하는 것을 볼 수 있다. 그리고 $\mathrm{Mo}$ 이 함유 되지 않은 시편에서는 $120 \mathrm{~min}$ 이후부터 감소하기 시작하는 것을 볼 수 있다. 이렇게 연신율이 감소하 게 되는 시간은 잔류오스테나이트의 분율이 감소하게 되는 시간과 큰 차이가 없음을 알 수 있다. 이는 2 단계 반응이 시작됨으로써 생성된 탄화물에 의한 영 향으로 판단할 수 있다.

그리고 $\mathrm{Mo}$ 이 함유되지 않은 시편에서는 $15 \sim 120$ $\min$ 까지 연신율의 변화는 7 8\% 정도로 변화의 폭 이 $\mathrm{Mo}$ 이 함유된 시편보다 상대적으로 적음을 알 수 있다. $\mathrm{Mo}$ 이 함유된 시편은 $15 \mathrm{~min}$ 에서는 $2.5 \%$ 의
연신율을 보이다가 $60 \mathrm{~min}$ 까지는 급격하게 증가하는 것을 볼 수 있다. 이는 1 단계 반응이 진행되면서 시 간에 따라 확산에 의한 고탄소 오스테나이트의 양이 증가하였음을 알 수 있다. 그리고 또한 $\mathrm{Mo}$ 이 함유 된 시편의 전체적인 반응이 $\mathrm{Mo}$ 이 첨가되지 않은 시 편보다 늦게 일어남을 볼 수 있다.

\section{5 경도특성의 변화}

각 온도에서 오스템퍼링 시간에 따른 경도 측정이 주는 의미는 단순히 경도 값을 측정하는 것뿐만 아 니라, 경도값의 변화로 1 단계 반응의 속도를 예측할 수 있다는 것이다. 일반적으로 오스템퍼링 온도에서 오스템퍼링 시간이 짧을 경우 매우 높은 경도값을 보이는데, 이는 반응 초기에 오스테나이트 기지로 탄 소확산이 충분히 일어나지 못하여 탄소가 전혀 확산 되지 못해 초기 오스테나이트 상태로 남아있던 미변 태 오스테나이트가 상온으로 냉각 시 마르텐사이트로 변태되며, 이와 함께 약간의 탄소를 고용한 준안정 오스테나이트들이 경도 시험 시 압입자의 하중을 받 아 응력 유기 마르텐사이트로 변태되었기 때문이다.

반응 초기로부터 오스템퍼링 시간이 길어질수록 경 도값은 일정영역으로 감소하며 유지하게 된다. 이때 일정하게 유지되는 시점이 $\mathrm{t} 1$ 즉, 1 단계 반응의 종 료시점을 의미한다. 실제로 $\mathrm{ADI}$ 에서 1단계 반응의 시점을 측정하는 중요한 방법 중에 하나이기도 하다.

Fig. 8는 오스템퍼링 시간에 따른 로크웰 경도값을 나타낸 것이다. 오스템퍼링 시간에 따른 전체적인 경 도 분포의 변화는 시간이 경과 할수록 경도가 낮다 는 사실을 확인할 수 있다. 이는 열처리 시간이 경 과함에 따라 고탄소 오스테나이트 분율이 증가하고, 페라이트 내에 탄소 과포화도가 감소하기 때문이다.

경도값의 변화는 제품의 가공성과 직결되기 때문에 매우 중요한 요인이다. 그리고 경도변화 곡선을 보면 $\mathrm{t} 1$ 을 예측 할 수가 있다. $\mathrm{t} 1$ 이 시작됨으로서 재료 내에 고탄소 안정화된 오스테나이트양이 증가하게 되 고 마르텐사이트는 감소하기 때문에 급격한 경도변화 가 발생하는 시간을 보통 $\mathrm{t} 1$ 으로 판단한다.

$\mathrm{Mo}$ 이 첨가된 시편의 $\mathrm{tl}$ 은 $30 \mathrm{~min}$ 전후로 시작되 었음을 짐작 할 수 있다. 이에 반해 $\mathrm{Mo}$ 이 첨가되지 않은 시편에서는 $\mathrm{Mo}$ 이 첨가된 시편에 비해 급격한 경도변화가 이미 $15 \mathrm{~min}$ 부터 시작되고 있음을 볼 수 


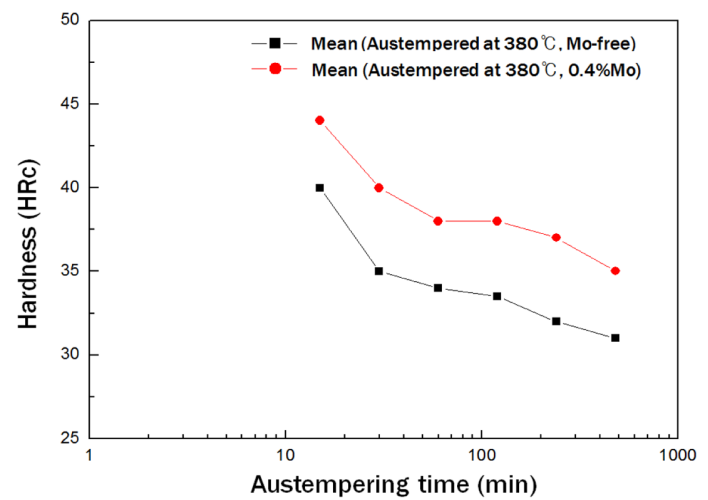

Fig. 8. Variation of hardness with austempering time.

가 있다. 이는 $15 \mathrm{~min}$ 이전에 1 단계 반응이 시작되 었음을 알 수 있다.

\section{4. 결 론}

$\mathrm{Cu}$ 가 함유된 구상흑연주철에 $\mathrm{Mo}$ 를 첨가하여 $900^{\circ} \mathrm{C}$ 에서 $150 \mathrm{~min}$ 동안 오스테나이타이징 한 후, $380^{\circ} \mathrm{C}$ 에서 $15 \sim 480 \mathrm{~min}$ 동안 오스템퍼링 처리된 기 계적 특성의 조사에 대해서 다음과 같은 결론을 내 렸다.

1. $\mathrm{XRD}$ 분석을 통해 $\mathrm{Mo}$ 이 함유된 시편에서는 $240 \mathrm{~min}, \mathrm{Mo}$ 이 함유되지 않은 시편에서는 $120 \mathrm{~min}$ 후부터 잔류 오스테나이트 분율이 감소하는 것을 볼 수 있다. 이는 2 단계 반응의 시작으로 인해 고탄소 안정 오스테나이트가 페라이트와 탄화물로 분해되었 음을 알 수 있다.
2. 2 단계 반응이 시작된 시간 이후에도 인장강도 및 항복강도에는 큰 변화는 없었다. 이는 초기에 생 성된 탄화물의 양이 인장강도와 항복강도에 크게 영 향을 미치지 않음을 알 수 있다.

3. 연신율은 $60 \mathrm{~min}$ 이후부터 감소하는 것을 알 수 있다. $\mathrm{Mo}$ 가 함유된 시편에서는 $240 \mathrm{~min}$ 부터 급 격하게 감소하는 것을 볼 수 있다.

4. 잔류오스테나이트 분율과 기계적 특성을 종합하 면 $\mathrm{Mo}$ 이 함유된 시편은 $\mathrm{Mo}$ 이 함유되지 않은 시편 보다 더 많은 변태 시간을 요구 한다는 것을 알 수 있다.

\section{References}

1. H. Bayati, R. Elliott and G. W. Lorimer : Materials Science and Technology, 11 (1995) 776.

2. N. Darwish and R. Elliott : The Institute of Materials (1993) 882.

3. Yanxiang Li and Xiang Chen : Materials Science and Engineering, A308 (2001) 277.

4. R. C. Voigt and R. Bendaly : AFS Transactions, 72 (1985) 453.

5. Susil K. Putatunda : Materials Science and Engineering, A297 (2001) 31.

6. R. C. Voigt : Cast Metal, 2 (1989) 71.

7. S. I. Lee, Y. K. Oh and G. C. Jun : JuJo, 17 (1997) 286.

8. B. Kovacs : AFS Transaction, 75 (1991) 281.

9. D. J. Moore, T. N. Rouns and K. B. Rundman : AFS Transaction, 103 (1985) 705. 